\title{
EDitorial
}

\section{New paradigms in the teaching of surgery for medical students}

\author{
Cristina P. Camargo ${ }^{1}$ \\ Rolf Gemperli \\ José Otavio C. Auler Junior ${ }^{3}$
}

At the beginning of XIX Century, medical education aimed to produce "a cultured and highly educated gentleman with, quite secondarily, an adequate knowledge of medicine"l.

Since then, a lot of changes have happened related to technology, life science knowledge, population longevity, health guidelines.

Nowadays, the medical education aims to prepare a future physician to provide a better individual and population care considering costs in health assistance, stimulate innovation in health devices and treatment to improve the global health ${ }^{2}$.

Due to these facts, we are living a new medical education revolution. This revolution concerns an improvement in the educational process to attend new social and scientific demands.

To better understand these demands it is interesting to consider some aspects:

$\checkmark$ the global survival rate increase;

$\checkmark$ medicine integrated into technology;

$\checkmark$ economic issues of health system;

$\checkmark$ the exponential growth in medical knowledge;

$\checkmark$ the physician needs to identify bias, incorrect results to deal with complex health challenges ${ }^{3}$.

In summary, the medical, educational system must prepare the student to accomplish the multiple tasks demands using critical thinking. For this purpose, the clerkship needs to implement some learning strategies based on neurological bases for learning, educational methods and innovative technology (apps, online communications).

1. Disciplina de Cirurgia Plastica, Faculdade de Medicina FMUSP, Universidade de São Paulo, Sao Paulo, SP, BR. Division of Plastic Surgery, Department of Surgery, School of Medicine, Laboratory of Microsurgery and Plastic Surgery (LIM-04), University of São Paulo, SP, Brazil. https:// orcid.org/0000-0002-3134-0003

2. Disciplina de Cirurgia Plastica, Faculdade de Medicina FMUSP, Universidade de Sao Paulo, Sao Paulo, SP, BR. Full Professor and Head, Division of Plastic Surgery, Department of Surgery, School of Medicine USP, São Paulo, SP, Brazil. Email: rolf.gemperli@fm.usp.br; https://orcid.org/00000001-9913-6079.

3. Faculdade de Medicina FMUSP, Universidade de Sao Paulo, Sao Paulo, SP, BR. Dean of FMUSP, Full Professor and Head, Division of Anesthesiology, School of Medicine, Laboratory of Anesthesiology (LIM-08), University of São Paulo, SP, Brazil. Email: jose.otavio@fm.usp.br; https://orcid. org/0000-0002-3919-1743

Correspondence: Cristina Camargo. Av. Brigadeiro Luis Antonio, 4161. CEP: 01401-001 SãoPaulo, SP, Brazil. Email: consultoriodracristina@gmail.com 
Some countries such as Europe and the United States of America have governmental organizations to standardize and create valid methods for educational purposes ${ }^{4}$. Even though we do not have this kind of support in our country; we believe the University of São Paulo has the potential and knowledge to create some pillars for this objective.

Due to these reasons, we invited some educators from the University of São Paulo, Harvard University and Fundação Leman institute to expose their ideas and knowledge about medical education.

In this issue, Dr. Fregni et al. article showed neuronal via for implicit and explicit memory. The authors discussed the concept of "fire together wire together" that ultimately transforms the short memory to a long-term and retrieval memory. A long-term memory will allow a better student performance in intern and residency program to achieve competence and proficiency for life.

The next two articles are related to the literature review. The authors reviewed different methods to teach basic surgical skills for undergraduate students.

These methodological approaches highlighted the importance of direct supervision, the necessary number of repetitions, the rationale of each step to compound the surgical procedure (knots, suture, hand hygiene, etc.). The student must understand how, why and how they are training a specific skill (Miller's pyramid).

Another challenge in the education context to overcome is the knowledge assessment; most of the available evaluations models are subjective and not efficient (long-term memory acquisition). In this issue of Revista de Medicina - Faculdade de Medicina da Universidade de São Paulo, we proposed some objectives and structured models to assess knowledge. The assessment process should be done both during the course (formative assessment) as well as at the end of it (summative assessment). The advantage of formative evaluations allows the clerkship modify and tailor some topics and skills according to student response. A summative evaluation allows an overall student assessment.

Finally, we interviewed Dr. Thiago Rached Pereira from Letrus. The idea of this last article was to underline the importance of overall education innovations and the new tools to apply to the learning process.

We invite all the teachers and students to read these articles and reflect on the challenges and ideas we will face during the medical education process.

\section{References}

1. The aim of medical education. Brit Med J. 1957;2(5044):565-6. Available from: https://www.ncbi.nlm.nih.gov/pmc/ articles/PMC1962350/pdf/brmedj03119-0049.pdf.

2. Morrissey B, Heilbrun ME. Teaching critical thinking in graduate medical education: lessons learned in diagnostic radiology. J Med Educ Curric Dev. 2017;20(4):1-5. doi: 10.1177/2382120517696498.

3. European Respiratory Roadmap. Healthcare Professionals. Medical education and training. Amsterdam: European Respiratory Society; 2011. Chap. 4, p.50-8 [cited 2018 Febr $9^{\text {th }}$. Available from: http://www.ersroadmap.org/ healthcare-professionals/medical-education-and-training-chapter-4/item/medical-education-and-training.html.

4. General Medical Council. The state of basic medical education. Reviewing quality assurance and regulation. London: FSC; 2010 [cited 2018 Febr $9^{\text {th }}$ ]. Available from: http://www.ub.edu/medicina_unitateducaciomedica/documentos/ The $\% 20$ State $\% 20$ of $\% 20$ Medical $\% 20$ Education\%20GMC.pdf. 